\title{
Screaming Yeast: Sonocytology, Cytoplasmic Milieus, and Cellular Subjectivities
}

\section{Citation}

Roosth, Sophia. 2009. Screaming yeast: Sonocytology, cytoplasmic milieus, and cellular subjectivities. Critical Inquiry 35, no. 2: 332-350.

\section{Published Version}

doi:10.1086/596646

\section{Permanent link}

http://nrs.harvard.edu/urn-3:HUL.InstRepos:11596975

\section{Terms of Use}

This article was downloaded from Harvard University's DASH repository, and is made available under the terms and conditions applicable to Other Posted Material, as set forth at http:// nrs.harvard.edu/urn-3:HUL.InstRepos:dash.current.terms-of-use\#LAA

\section{Share Your Story}

The Harvard community has made this article openly available.

Please share how this access benefits you. Submit a story.

\section{Accessibility}




\title{
Screaming Yeast: Sonocytology, Cytoplasmic Milieus, and Cellular Subjectivities
}

\author{
Sophia Roosth
}

That we have no ears to hear the music the spores shot off from basidia make obliges us to busy ourselves microphonically.

—John CAGE, A Year from Monday (1967)

\section{Introduction}

Saccharomyces cerevisiae, commonly known as yeast, is a unicellular fungus with a cell cycle similar to that of humans. The first eukaryote to have its genome fully sequenced and a standard model organism in biology research, ${ }^{2}$ yeast is an organism that lends itself to multisensory experiences. It has been imaged extensively with light and atomic force microscopy, and anyone who has seen the bottom of a pint glass or walked past a bakery can speak to Saccharomyces cerevisiae's olfactory and gustatory allure. It is fitting, then, that this species is also the first to have its cellular noises amplified and recorded.

Sonocytology, a recently developed technique within nanotechnology research, uses a scanning probe microscope to record the vibrational movements of cell walls and amplifies these vibrations so that humans can hear them. Yeast cells vibrate approximately one thousand times per sec-

1. John Cage, A Year from Monday: New Lectures and Writings (Middletown, Conn., 1967), p. 34; quoted in Douglas Kahn, Noise, Water, Meat: A History of Sound in the Arts (Cambridge, Mass., 1999), p. 195.

2. The trajectory of twentieth-century biosciences and biotechnology is closely tied to yeast, an organism with significant economic uses. Given its abundance, economic and industrial significance, and the wealth of scientific information on it, yeast is often at the vanguard of new scientific experimentation. Yeast was instrumental in the early development of the biotechnology industry. It was present when the Royal Swedish Academy of Engineering Sciences coined the term biotechnology in 1943 to designate a new initiative of the academycreated at the urging of the secretary of the Brewing Research Society-that was devoted to pursuing biological solutions to wartime food, energy, and pharmaceutical shortages. Edy Velander, a MIT-trained engineer, was named the director of the new section. He proposed the name bioteknik "to bring together applications which arise while one is learning to influence biological processes scientifically and exploit them technologically in an industrially organized activity, for example in industrial yeast cultivation, in the food industries for processing and improving the raw products as well as for the preparation and conservation of foodstuffs" (Edy Velander, "Bioteknik," IVA: Teknisk-vetenskapligforskning, 15 Feb. 1943, p. 1; quoted in Robert Bud, The Uses of Life: A History of Biotechnology [Cambridge, 1993], p. 96). 
ond. Humans can hear any vibration that has a periodicity in the range of twenty to twenty-thousand vibrations per second $(\mathrm{Hz})$. The vibration of yeast cells is well within the frequency range of human hearing - in musical terms "about a C-sharp to D above middle C"- - but the amplitude of their vibration is too low to be within normal hearing range (the cell wall is displaced only three nanometers each time it vibrates). ${ }^{3}$ By amplifying the vibrations of cells, researchers are essentially "turning up the volume" on cellular vibrations ("SD," p. 32). How are raw cellular vibrations converted into cellular sounds that scientists interpret as conveying meaningful information regarding the dynamism of cellular interiors? What are the conditions that enable scientists to describe cells as actors capable of "speaking" or "screaming," and how might listening to cellular sounds eventually change how scientists think about cells?

This essay will analyze how sonification constitutes scientific objects and how scientists use sound to represent these scientific objects as subjects. While subjectivity implies the ability to speak to one's conditions it also suggests that actors' utterances are conditioned by epistemic and ideological regimes. Sonocytology renders ambiguous the distinction between cells speaking and cells being spoken for. Specifically, I will attend to how raw sound is transformed into signals-that is, how scientists convert inchoate cellular vibrations into meaningful scientific data. In order to answer the question of how sound might alter the way in which scientists perceive and understand cellular activity, I will first describe how sonocytology developed and how scientists and popular media have turned to metaphor in order to make sense of cellular noise. I will then focus on two epistemological effects of using sound scientifically to explore otherwise inaccessible spaces. The first concerns the ways we think of organisms in their environment and in relation to other organisms, and the second bears on the question of how we think about the interiority of an organism as a stage on which dynamic biological processes are performed.

Jim Gimzewski, a scientist in the Department of Chemistry and Biochemistry at the University of California, Los Angeles, is best known for

3. Mark Wheeler, "Signal Discovery?" Smithsonian Magazine 34 (Mar. 2004): 32; hereafter abbreviated "SD."

Sophia Roosth is a doctoral candidate in the programs of History, Anthropology, and Science, Technology, and Society at the Massachusetts Institute of Technology. Her email is sroosth@mit.edu 
nanotechnology research he conducted while at the IBM Zurich Research Laboratory, where he built the highly publicized molecular abacus and molecular wheel. ${ }^{4}$ A celebrity in the nanotech world, he has received numerous honors and prizes, including the prestigious Feynman Prize in Nanotechnology.

In 2004 Gimzewski and his graduate student Andrew Pelling used an atomic force microscope (AFM) to record the nanomechanical motion of yeast cells. Atomic force microscopy has been used for probing the surface of E. coli, imaging biomolecular reactions as they occur, measuring the molecular movement of cardiomyocytes (heart muscle cells that contract rhythmically in culture), and tracking the movements of flagella and cilia. Gimzewski's original intention was to record the movement of cardiomyocytes, which were sent to him by Carlo Ventura, a Sardinian medical researcher he had met at a conference in 2001. Gimzewski's stem cells were scheduled to arrive from Sardinia on 11 September 2001, but in the heightened state of national security the stem cells were deemed a potential threat and seized by customs. ${ }^{5}$ Frustrated and impatient to begin his work with the AFM, Gimzewski borrowed a yeast culture from colleagues in a nearby lab and was surprised to discover that yeast vibrate with a regular periodicity.

The AFM was manufactured in the 1980 s and is now indispensable to nanotechnology work. While light microscopes cannot resolve objects smaller than half the length of a light wave, the AFM resolves this problem, which scientists term the Rayleigh limit, by using a probe to map the topology of the object being imaged. As a tiny cantilever (its tip is less than ten nanometers wide) is displaced by the surface of an object, a piezoelectric crystal converts nanomechanical motion into voltage, creating a map of the surface. However, instead of dragging a probe over the surface of a sample, Gimzewski held the AFM probe stationary on the surface of a yeast cell so that the oscillations of its cell wall could be traced. Yeast cells, about five microns in length, have walls much more rigid than most mammalian cells, making it easier to rest a microscopic probe on their surface in order to detect cellular vibrations. Gimzewski discovered that yeast cells vibrated rhythmically and that the periodicity of the vibration was within the range of human

4. See Maria Teresa Cuberes, Reto Schittler, and James Gimzewski, "Room-Temperature Repositioning of Individual $\mathrm{C}_{60}$ Molecules at Cu Steps: Operation of a Molecular Counting Device," Applied Physics Letters 69, no. 20 (1996): 3016-18, and Gimzewski et al., "Rotation of a Single Molecule within a Supramolecular Bearing," Science, 24 July 1998, pp. 531-33.

5. See Margaret Wertheim, "Buckyballs and Screaming Cells: The Amazing Miniature World of UCLA Chemist Jim Gimzewski," LA Weekly, 4 Apr. 2003, pp. 28-33. 
hearing. Using a freeware program, he converted the vibrations recorded by the AFM into a sound file. Gimzewski claims that sonocytology is preferable to other techniques for rendering cellular interiors because it is "not invasive and does not depend on the use of chemical dyes, fluorescent markers, or quantum dots." ${ }^{\prime} \mathrm{He}$ argues that the naturally occurring synchronized movement of motor proteins "cannot be observed by traditional cytological methods" ("L," p. 1150) and are "too small and fast to be seen on video." 7

How do acoustic technologies change what it means for something to be audible, given that sound is by definition a vibration that can be heard by an organism? Jonathan Sterne defines sound as "a product of the human senses and not a thing in the world apart from humans." ${ }^{\text {" Extending }}$ Sterne's definition, under the rubric of sound I include any vibration perceptible to any organism; that is, sound is the sum total of Michel Serres's "global tympanum"- a soundscape filled with "waves rather than spaces" that "moulds and indents" listening organisms. ${ }^{9} \mathrm{~A}$ vibration is not necessarily audible, and sounds are not inherently meaningful. Only mechanical oscillations within a small range of frequency and amplitude are audible without technical manipulation.

Sound is any vibration within the range of an organism's hearing or, since the advent of acoustic technologies, of an organism-acoustic machine assemblage. Because sound is necessarily related to a biological sensorium and assumes a tuned-in body, it has a semiotic component that is parsed in historically and socially specific contexts. If a signal is not deemed meaningful by a listening body then it is noise- "irrelevant or superfluous information" that can interfere with the transmission of information. A signal, in contrast, is a sound that a listener regards "as conveying information about the source from which it comes." ${ }^{10}$

Cyrus Mody, in his ethnographic account of how sound structures laboratory experimentation and contributes to the construction of scientific knowledge, argues that the separation of good sound from acoustic contamination is an evolving process that is both contingent

6. Andrew Pelling et al., "Local Nanomechanical Motion of the Cell Wall of Saccharomyces cerevisiae," Science, 20 Aug. 2004, p. 1150; hereafter abbreviated "L."

7. Quoted in anon., "Freight-Carrying Proteins Vibrate Walls of Cells,"

www.eurekalert.org/features/kids/2004-08/aaft-fpv020805.php

8. Jonathan Sterne, The Audible Past: Cultural Origins of Sound Reproduction (Durham, N.C., 2003), p. 11.

9. Michel Serres, Les Cinq Sens (Paris, 1998), pp. 180-81; quoted in Steven Connor, "Michel Serres' Five Senses," in Empire of the Senses: The Sensual Culture Reader, ed. David Howes (Oxford, 2005), p. 324.

10. Oxford English Dictionary, 2 d ed., s.v. "noise" and "signal." 
and context specific. ${ }^{11}$ Apart from vibrations, which refer to a purely physical phenomenon, sound, noise, signal, music, voice, and scream each assume a listener who can make a judgment as to the ontology of an acoustic resonance. A listener designates a sound as music if he or she judges that someone composed it to be rhythmic, aesthetically pleasing, or otherwise expressive. Claiming that a sound is a voice imbues the sound's source with the agency to utter sounds that convey information. A scream is inarticulate speech made by a human to express extreme pleasure or pain. Nonhuman animals are rarely described as screaming; they screech, squeal, yelp, or howl. Attending to how cellular oscillations are alternately described as sound, noise, signals, music, singing, or speaking reveals the ways in which listeners interpret cellular agency and subjectivity.

Much in science studies has been written on the role of visualization in scientific research. Indeed, visual concerns and metaphors are central to the theories used in Science and Technology Studies (STS); STS scholars often speak of Bruno Latour and Steve Woolgar's "inscription devices," Latour's "drawing things together," David Kaiser's "drawing theories apart," Jacques Derrida's “traces," Donna Haraway's "god's eye view from nowhere," Ian Hacking's homo depictor, and Walter Benjamin's unconscious optics. ${ }^{12}$ In addition, scholars have learned to think about panopticism and the anatomy of power from Foucault, feminist and

11. See Cyrus Mody, "The Sounds of Science: Listening to Laboratory Practice," Science, Technology, and Human Values 30, no. 2 (2005): 175-98. Henning Schmidgen provides an earlier example of the disruption of laboratory work by sound. Adolphe Hirsch, director of the Neuchâtel observatory in Switzerland, began to experiment with using chronoscopes to measure the reaction time of astronomers in 1861. Throughout his experiments he was disturbed by the humming of his own lab instruments and by the ringing of bells outside. Hirsch "saw his efforts to precisely determine and communicate time threatened by another, more ancient system for communicating time" (Henning Schmidgen, "Time and Noise: The Stable Surroundings of Reaction Experiments, 1860-189o," Studies in History and Philosophy of Biological and Biomedical Sciences 34, no. 2 [2003]: 259-60).

12. See Bruno Latour and Steve Woolgar, Laboratory Life: The Construction of Scientific Facts, 2d ed. (Princeton, N.J., 1986); Latour, "Drawing Things Together," in Representation in Scientific Practice, ed. Michael Lynch and Woolgar (Cambridge, Mass., 1990), pp. 19-68; David Kaiser, Drawing Theories Apart: The Dispersion of Feynman Diagrams in Postwar Physics (Chicago, 2005); Jacques Derrida, Of Grammatology, trans. Gayatri Chakravorty Spivak, 2d. ed. (1976; Baltimore, 1993) and Specters of Marx: The State of the Debt, the Work of Mourning, and the New International, trans. Peggy Kamuf (New York, 1994); Donna Haraway, "Situated Knowledges: The Science Question in Feminism and the Privilege of Partial Perspective," Feminist Studies 14, no. 3 (1988): 575-99; Ian Hacking, Representing and Intervening: Introductory Topics in the Philosophy of Natural Science (Cambridge, 1983); and Walter Benjamin, "The Work of Art in the Age of Mechanical Reproduction," Illuminations, trans. Harry Zohn, ed. Hannah Arendt (New York, 1969), pp. 217-51. For more examples of "oculocentric" terminology in STS, see Mody, "The Sounds of Science." 
psychoanalytic theories have introduced the issue of the gaze, and postcolonial studies has exported the I/eye.

In contrast, with the exception of recent analyses of the scientific uses of space sounds, underwater sounds, and laboratory sounds, acoustic technology in scientific research has been understudied and undertheorized by STS scholars. ${ }^{13}$ An important special issue of Social Studies of Science fails to examine sound as scientific data, though the editors do open up a critical dialogue between STS and sound studies, emphasizing that STS can offer "a focus on the materiality of sound, its embeddedness not only in history, society, and culture, but also in science and technology and its machines and ways of knowing and interacting." ${ }^{14}$ In his study of acoustic contamination in laboratory science, Mody shows that researchers diagnose problems in their microscopes by listening to them, a practice that functions as an auditory transmission of tacit knowledge that imparts a more "embodied interaction with the instrument." ${ }^{\prime 5}$ In the end, he calls for a more anthropologically motivated thick description of the status of all the senses in laboratory practice. While Mody examines how acoustic contamination dictates the structure of experimentation in laboratories, I attend to the status of sound as primary scientific data-sound as scientific signalrather than noise. Understanding the separation of meaningful data from experimental contamination as a culturally determined judgment, I will examine how scientists make sense of cellular noise. Parsing cellular signals from noise, I argue, is determined by scientists' understanding of cells as subjects capable of speaking to their conditions.

What kinds of new soundscapes are created by acoustic technologies and how are they listened to, explored, and made sense of by scientists through the mediation of technology? ${ }^{16}$ In explicating how sound affects the way we understand cellular interiors, I will employ Georges Canguilhem's use of the concept of milieu — an array of decentered and mutually influential relations between an organism and its surrounding environment - to argue that sound clues us into the material situatedness of cel-

13. On the scientific use of space sounds, see Emma Johnson and Robert Lecusay, "In Space, NASA Can Hear You Scream," paper delivered at the Annual Meeting of the Society for the Social Studies of Science, Pasadena, Calif., 20-22 Oct. 2005; on underwater sounds, see Stefan Helmreich, "An Anthropologist Underwater: Immersive Soundscapes, Submarine Cyborgs, and Transductive Ethnography," American Ethnologist 34, no. 4 (2007): 621-41; on laboratory sounds, see Mody, "The Sounds of Science."

14. Trevor Pinch and Karin Bijsterveld, "Sound Studies: New Technologies and Music," Social Studies of Science 34, no. 5 (2004): 636.

15. Mody, "The Sounds of Science," p. 188.

16. Soundscape is a term coined by R. Murray Schafer in the late 1960s to emphasize the ecology of sound. See R. Murray Schafer, The New Soundscape (Scarborough, Ontario, 1969). 
lular life. ${ }^{17}$ By drawing listeners into the environment of its source, sound creates a soundscape in which the different milieus of people and cells can resonate. Finally, by considering the diverse meanings of transductionthe conversion of a signal from one medium to another-I will explore how sound travels through different material environments and how it is converted into scientific information.

After addressing the influence of acoustics on the understanding of cellular milieus, I turn my attention to the understanding of cellular temporality, asserting that sound makes it possible to access in situ the internal biological processes of bodies and cells, allowing us to understand bodies and cells in time and in context. While STS scholars have critiqued science for reducing subjects to experimental objects, I will examine how scientists make sense of cellular noises and more specifically how sonification constructs a particular form of technologically and socially mediated cellular subjectivity.

\section{Listening to Cells}

When Gimzewski examined the data recorded by the AFM and realized that yeast vibrate regularly, he went online and downloaded Awave Audio, a computer program that could convert the vertical deflection data into a WAV file. ${ }^{18}$ When he ran the program on the lab computer and turned on the speakers an ethereal noise filled the laboratory. ${ }^{19}$ Beginning to experiment with the noise produced by yeast, he recorded the vibrations they made at different temperatures and in different solutions. Adding sodium azide, a chemical that inhibits cellular metabolism, to the yeast caused a noise that sounded like radio static. Gimzewski believes this sound is an indexical representation of the Brownian motion of molecules, since sodium azide stops all ATP-driven nanomechanical activity. When he doused the yeast in alcohol, the pitch of the vibration increased. In an interview, he claimed that: "it screams. It doesn't like it. Of course, yeast produces alcohol as in beer production, but if you put strong alcohol like

17. See Georges Canguilhem, “The Living and Its Milieu” (1952), trans. John Savage, Grey Room 3 (Spring 2001): 7-31; hereafter abbreviated "LM."

18. "We took the AFM vertical deflection data straight off the photodiode and logged it as a 16-bit ASCII text file, which was basically one column of vertical deflection values. The time between each value is then $1 / \mathrm{f}$, where $\mathrm{f}$ is the sample frequency (typically $10 \mathrm{kHz}$ or more). Anyway, both Awave and SpectraPRO allowed us to just import these ASCII files with the appropriate sampling rate and save them as WAV. Since they are oscillatory they are just like any electronic sound file. The only manipulation was normalization to $12-16 \mathrm{~dB}$ which made the files louder. Otherwise all the frequency information and relative amplitude modulation was retained" (Pelling, conversation with the author, 20 Nov. 2006).

19. To listen to recordings of cellular sounds, see www.darksideofcell.info 
Absolut vodka on it, if you like, then it screams. It screams. It doesn't like it." He speculates that this "screaming" is the sound of molecular pumps working overtime to expel the alcohol. ${ }^{20}$

When he says that when doused with alcohol yeast "scream" because they don't like it Gimzewski endows yeast with agency. Characterizing the sounds made by yeast as screaming seems like an odd descriptive choice, as it suggests that Gimzewski's experimental interventions cause the yeast pain. Popular-science articles about sonocytology picked up this metaphor, describing Gimzewski as the "master of this cellular torture chamber." ${ }^{21}$ The suffering of model organisms, which makes most scientists uncomfortable, is usually expunged from professional and popular accounts of scientific research..$^{22}$ Screaming is not just any kind of signal; it is an interrelational, emotionally loaded message uttered either in pleasure or pain: "screams demand urgent or empathetic responses and thereby create a concentrated social space bounded by their audibility." ${ }^{23}$ As a mode of communication, screaming is usually only attributed to humans, but here it is more than a response to environmental crisis. Interpreting cellular noise as screams forces attention on the shared cellularity of humans and yeast, as well as the fact that yeast are model organisms that stand in for humans in biomedical experiments. Endowing yeast with agency by calling upon an anthropocentric model of subjectivity, scientists transform objects of scientific research into cellular subjects.

The sounds made by yeast provoke flights of metaphorical fancy as scientists and journalists alike struggle to find words to describe something new in familiar terms. Articles on Gimzewski's technique have likened the sound to the whistling of singing whales and have compared the AFM to a microphone, a new musical instrument, or, as Pelling suggests, a record needle. ${ }^{24}$ Gimzewski tells reporters that if yeast were the size of humans

20. "Researchers Listen to Yeast Cells," All Things Considered, 19 Aug. 2004, National Public Radio; hereafter abbreviated "R."

21. Catherine Zandonella, "Dying Cells Dragged Screaming under the Microscope," Nature, 8 May 2003, p. 106.

22. See Michael Lynch, "Sacrifice and the Transformation of the Animal Body into a Scientific Object: Laboratory Culture and Ritual Practice in the Neurosciences," Social Studies of Science 18, no. 2 (1988): 265-89.

23. Kahn, Noise, Water, Meat, p. 345.

24. For singing whales, see Karen Lurie, "Small World," Science Central News, 4 Mar. 2004, www.sciencentral.com/articles/view.php3?article_id=218392191; for the microphone analogy, see Sam Jaffe, "A Symphony beneath Your Skin? One Scientist Turns up the Volume on Cellular Chatter," Popular Science 265, no. 3 (2004): 50; on the comparison to a new musical instrument, see www.darksideofcell.info/zkminterview1o.mov; for the comparison to a record needle, see "SD," p. 32. Comparing the AFM to a record needle raises the question of whether a vibration constitutes a signal by virtue of its audibility. Rainer Maria Rilke, in "Primal Sound" (1919), asks "what variety of lines, then, occurring anywhere, could one not put under the 
their sounds would be closer to the volume of ordinary conversation than of loud music and that "if you were to shrink down to the cell's size, it would be like holding a transistor radio to your ear." ${ }^{25}$ When Gimzewski and Pelling published their findings in Science, representatives of the Maharishi Mahesh Yogi approached them, thinking that they had "discovered 'the language of life."' 26

While the sounds produced are conversions of surface vibrations of yeast cells, Gimzewski believes these sounds provide access to the workings of the cellular interior by indexically signifying cellular metabolism and movement. ${ }^{27}$ Describing the technique he developed, Gimzewski says: "We gently touch a cell, a living cell and we listen.... They actually produce a kind of music and you can hear it. ${ }^{28} \mathrm{He}$ says the music made by the cell is "amazing" ("R") and "beautiful." ${ }^{29}$ This characterization as music is predicated upon a definition of sound as something audible not only to the ear but to the ear with the aid of technical amplification. Like Cage's basidia spores, yeast are already making music; we just have to heed Cage's advice and "busy ourselves microphonically" in order to hear it. Calling these sounds music actually casts the organism as composer, extending authorship and artfulness into the natural world.

Gimzewski compares listening to the vibrations of yeast to standing outside of a factory and hearing the hum and beat of machines operating inside the factory walls, pointing out that during the Industrial Revolution

needle [of a phonograph] and try out? Is there any contour that one could not, in a sense, complete in this way and then experience it, as it makes itself felt, thus transformed, in another field of sense?" (quoted in Friedrich Kittler, Gramophone, Film, Typewriter, trans. Geoffrey Winthrop-Young and Michael Wutz [Stanford, Calif., 1999], p. 41). Kittler responds to Rilke's question by claiming that "before [Rilke], nobody had ever suggested to decode a trace that nobody had encoded and that encoded nothing" (Kittler, Gramophone, Film, Typewriter, p. 44).

25. Jaffe, "A Symphony beneath Your Skin," p. 50.

26. Clive Thompson, "Listening for Cancer," New York Times Magazine, 12 Dec. 2004, p. 82. Lily Kay notes that "the language of life" is a metaphor imbued with "operational force" that, although having a long history in Western culture, was made literal and given scientific legitimacy by linguistics only in the 1950 a and 1960 (Lily Kay, Who Wrote the Book of Life? A History of the Genetic Code [Stanford, Calif., 200o], p. 1). In a Derridian turn, sonocytology extends the linguistic metaphor of life by listening for uttered signs rather than decoding written words.

27. Charles Sanders Peirce defines three types of signs: the icon, the index, and the symbol. The index is a sign that has some kind of physical relationship to its referent. Or, as Peirce explains more lyrically: "Anything which focuses the attention is an indication. Anything which startles us is an indication, in so far as it marks the junction between two portions of experience" (Peirce, "What Is a Sign?" [1894], The Essential Peirce: Selected Philosophical Writings, ed. Peirce Edition Project, 2 vols. [Bloomington, Ind., 1998], 2:8).

28. Lurie, "Small World."

29. Thompson, "Listening for Cancer," p. 82. 
trained mechanics could diagnose what was wrong with a machine just by listening to it (see "R"). Extending and concretizing this analogy between cells and machines, Gimzewski is currently applying sonocytology to clinical diagnostics by listening for the difference between healthy and cancerous cells.

Gimzewski believes that sonocytology has potential diagnostic applications because cancerous cells metabolize ATP more quickly and therefore vibrate at a higher frequency than noncancerous cells. His ultimate goal is for clinicians to be able to detect cancer at an early stage by listening to cells. However, one obstacle to a medical application of sonocytology is the fact that mammalian cell membranes are much less rigid than the cell walls of yeast. Nonetheless, Gimzewski has begun collaborating with Michael Teitell, an immunologist who develops animal models for lymphomas. ${ }^{30}$ Teitell exposes human and mouse osteocytes to chemical mutagens, and Gimzewski tries to identify which cells are cancerous using sonocytology.

Cellular sounds are not meaningful to the cells, but they could be made meaningful through human audition. Other scientists have suggested that the vibrations picked up by the AFM are signals the cells use to communicate with one another. Kerry Bloom, a mycologist at the University of North Carolina, points out that it was a "big surprise when people played rock music to plants, and there was a chemical change inside the cell of the plant when you played the Stones at high volume. And so now I would argue the same thing with anything with a cell wall. Now the expectation is some physical output that can be another level of signaling" ("R"). Inscription devices turn occurrences into events, and the AFM turns sonic and informatic noise into a meaningful message. ${ }^{31}$ In attempting to make sense of cellular noise, Bloom speaks on the yeast's behalf.

\section{Acoustic Milieus}

Emily Thompson defines a soundscape as "simultaneously a physical environment and a way of perceiving that environment; it is both a world and a culture constructed to make sense of that world." Bound up in the process of turning sound into data is the listener's culture, the environ-

30. See Wertheim, "Buckyballs and Screaming Cells," p. 33.

31. The distinction between occurrences and events is one of awareness; the act of looking or listening turns something that merely happens into something more momentous. Benjamin coined the term unconscious optics to refer to the camera's ability to bring a previously unnoticed movement to our conscious attention by substituting an "unconsciously penetrated space ... for a space consciously explored by man" (Benjamin, "The Work of Art in the Age of Mechanical Reproduction," pp. 236-37). Perhaps we could think of sonocytology as a technique of unconscious acoustics with which vibrations too small to be heard are brought to our attention. 
ment in which the sound reverberates, and "the material objects" within that environment "that create, and sometimes destroy, those sounds." That is, a listener is both acoustically and culturally immersed in soundscapes. ${ }^{33}$ But how does sound condition an organism's environment, and how does that environment affect which sounds count as signals and which are merely noise? Listening to cellular noises attunes scientists to the way each cell is embedded in, and in mutual relation to, its microenvironment. Symmetrically, just as cellular noises draw attention to a cell's immersion in extracellular environments (in this case, the constructed environment of the laboratory), the interpretation of cellular noise is embedded in the listener's culture. By tying cellular and cultural immersion together, we can see how listening to cells creates a space in which cellular and human milieus resonate.

Gimzewski's AFM is housed in a special darkened noise-free room, inside a thermally, acoustically, and electrically isolated chamber lined with foil on a vibration-free platform suspended in air. The care taken in isolating the AFM from any vibration is necessary in order to verify that the vibrations recorded are due to cellular activity and not to any external noise (here I mean noise both as external phenomena, in the sense of sound, and figuratively as a disturbance in a signal). The vibration of the AFM probe due to random external vibrations is less than the length of a single atom. Ironically, in order to listen to the vibrations of cells "in their natural state," a very artificial environment must first be constructed ("L," p. 1150).

As a relation between an organism or some other biological system and its ambient environment, a milieu is a landscape that influences and in turn is shaped by the organism that occupies it. The notion of milieu fastens organisms to the web of their environment's particularities, drawing attention to an organism's interaction with its environment and with the other organisms in it. In his explication of the conceptual evolution of milieu, Canguilhem writes that it "explains the passage from the notion of fluid as a vehicle to its designation as a medium [milieu]. The fluid is the intermediary between two bodies; it is their milieu; and to the extent that it penetrates these bodies, they are situated within it ("LM," p. 8). He continues: "Circumstances and surroundings still retain a symbolic value,

32. Emily Thompson, The Soundscape of Modernity: Architectural Acoustics and the Culture of Listening in America, 1900-1933 (Cambridge, Mass., 2002), p. 1.

33. Helmreich uses multiple registers of immersion and transduction to anchor his ethnographic account of his descent in Alvin, an underwater submersible. Immersion can alternately be used to describe being "in water, sound, or the medium of culture" (Helmreich, “An Anthropologist Underwater," p. 602). 
but milieu abandons any evocation other than a position indefinitely denied by exteriority. The now refers to the future, the here refers to its beyond, and so forth always ad infinitum. The milieu is really a pure system of relationships without supports" ("LM," p. 11).

In terms of soundscapes, sound can draw attention to the milieu in which an organism is situated; sound vibrations travel through air or water and refract off other objects inhabiting the milieu. It is important to note that all of the sounds Gimzewski recorded were differentiated by the type of environment in which the yeast cell was situated, which varied according to temperature, osmolarity, and the presence or absence of sodium azide or ethanol. The recorded sounds, as the index of cellular responses to extracellular circumstances, demonstrate the porosity of the cell wall, blurring the boundary between intracellular and extracellular landscapes.

The experience of listening reconstitutes a parallel situation for the listener's bodily relation to his or her environment. For instance, Julian Henriques describes the experience of listening to dub music as feeling "the pressure of the weight of the air like diving deep underwater ... making the experience imminent, immediate, and unmediated." Sound is a system of relations between at least two bodies. It requires an origin as well as a receiver to sense audible vibrations. While sound has a point of origin, there is no center to the space through which it is transmitted. Bodies are both situated within an acoustic space and are penetrated by it, as it "is a kind of space you are inside as well as outside and it is inside you as well as you being inside it." ${ }^{34}$ Compare Canguilhem's biological milieu to Marshall McLuhan's notion of auditory space:

It is the act of hearing that itself creates 'auditory space,' because we hear from every direction at once.... Auditory space, so crucial to architectural problems today, is usually defined as 'a field of simultaneous relations without center or periphery.' That is, auditory space contains nothing and is contained in nothing. It is quite unvisualizable, and, therefore, to the merely print-oriented man, it is 'unintelligible. ${ }^{35}$

Auditory space implies a listener who defines and demarcates it. That is, by definition auditory space must be a biological space, one inhabited by organisms making noise and listening to their own and others' sounds. Nei-

34. Julian Henriques, "Sonic Dominance and the Reggae Sound System Session," in The Auditory Culture Reader, ed. Michael Bull and Les Back (Oxford, 2003), pp. 452, 459.

35. Marshall McLuhan, "Inside the Five Sense Sensorium" (1961), in Empire of the Senses, p. 49; emphasis added. 
ther immaterial nor purely informatic, sound is a perceptual field requiring topographies, media of transmission, and listening bodies.

A series of milieus is folded into the practice of sonocytology. Each milieu is an array of relations linked to other milieus. There are the milieus of the scientist, who might be ensconced in a sound- and vibration-free room (manipulating the probe of an AFM, for example) or sitting in front of a computer listening to the sounds of yeast flood from speakers into the lab. There is also the milieu of the yeast cell; because the cell cannot be taken out of fluid without dying, it is suspended in a fluid "yeast extract" and flushed through a lattice with $5 \mu \mathrm{m}$ pores so that a yeast cell is trapped in each pore before being placed in a Petri dish and doused in yet another medium made of pulverized potatoes (" $L$," p. 1148). After being corralled and pinned by the tip of the AFM probe, the yeast vibrates in its isolated chamber. Beneath the cell wall lies a cytoplasmic milieu inhabited by organelles suspended in cytoplasm and motor proteins that transduce chemical energy from ATP into motor energy in order to build cellular scaffolding and traffic molecules through the cell. The transduction of sound from each of these milieus to the next constructs a soundscape where cellular processes become sensible to biologists, that is, once they have learned to interpret what they are hearing. Resonances scale the domains and temporalities of previously isolated milieus. ${ }^{36}$

An acoustic milieu, then, is a milieu shared by two (or more) organisms in relation to each other and to their surroundings. If "the milieu that is proper to man is the world of his perception," then listening to yeast creates a milieu that he shares with yeast ("LM," p. 26). It is within this thumping cytoplasmic milieu that we imagine ourselves when listening to cellular noise.

But listening occurs in time and cellular activity is dynamic, so we must also attend to the modes in which sound is transmitted through acoustic milieus. Sound is transduced as it travels through media and mediating machines. Transduction, as engineers use the term, refers to the technically mediated process by which mechanical vibrations are converted into electrical signals. Thompson argues that the technical and material development of transducers in the 1920 and 1930s significantly affected the

36. For Gilles Deleuze and Félix Guattari, "every milieu is coded ... but each code is in a perpetual state of transcoding or transduction. Transcoding or transduction is the manner in which one milieu serves as the basis for another, or conversely is established atop another milieu, dissipates in it or is constituted in it.... The milieus pass into one another; they are essentially communicating" (Gilles Deleuze and Félix Guattari, A Thousand Plateaus, trans. Brian Massumi, vol. 2 of Capitalism and Schizophrenia, trans. Massumi et al. [Minneapolis, 1987], p. 313). 
epistemology of sound: "scientists who used [electroacoustic transducers] began to effect similar transformations between sounds and signals in their minds, developing new ideas about the behavior of sound and the physical objects that produced it." ${ }^{37}$ That is, by turning sound into an electrical signal that could be amplified, manipulated, and transformed, acoustic technology turned sound into information that could be fruitfully studied by scientists and used as data for gathering information about natural phenomena.

Transduction has three definitions, all of which apply to sonocytology. Acoustic transduction is the conversion of a signal, such as a sound wave, from one medium to another. Biological transduction is the transfer of biological information from one organism to another or the translation of a stimulus into an electrical impulse. Technical transduction converts input energy into output energy of a different form by a transducer such as the piezoelectric crystal of an AFM or through a microphone..$^{88}$

Piezoelectricity defines the reversible conversion of mechanical energy into electricity. Microphones, for instance, transduce mechanical vibrations into electrical signals, while speakers do the reverse. In addition to microphones and speakers, a third kind of transducer is at work; the human sensorium can be understood as a device for converting mechanical energy, light, and chemical stimuli into electrical impulses:

Hearing is understood ... in terms of a work of transformation. Hearing takes what Serres calls the hard, le dur, and converts it into information, le doux, or the soft. This exchange is effected by the senses, or by the work of sensation, which, in turning raw stimulus into sensory information, also make sense of the senses, effecting a slight declination, or deflection within the word sens itself: sense becomes sense. These transformations are effected in every organism by

37. Thompson, The Soundscape of Modernity, p. 96.

38. A fourth definition of transduction mediates between the technical and the biological, referring to when a machine can predict new outputs based on prior experience of inputs and their resulting outputs, that is, through learning. Henriques suggests that transduction surpasses traditional binary compartmentalizations of the world: "A transducer is a device for achieving the escape velocity to leave the world of either/or and enter the world of either and both" (Henriques, "Sonic Dominance," p. 469). On the acoustic and biological resonances of transduction for thinking through the ways in which biological objects and spaces are perceived and performed through mediating technologies, see Adrian Mackenzie, Transductions: Bodies and Machines at Speed (London, 2002); Natasha Myers, "Animating Mechanism: Animations and the Propagation of Affect in the Lively Arts of Protein Modelling," Science Studies 19, no. 2 (2006): 6-30; and Helmreich, "An Anthropologist Underwater." 
a series of processes of transformation that Serres is wont to call 'black boxes.' 39

The yeast/AFM/human assemblage that performs sonocytology is a series of vibrations traveling through different media and converted into sound by mediating transducers..$^{40}$ The kinetic motion of motor proteins becomes a cytoplasmic rumble that vibrates the cell wall, which exerts pressure on a cantilever, causing the piezoelectric crystal to convert the deflection into an electrical output. A graphic trace of its deflection is created, which is then converted using a computer program into an electrical signal sent through a pair of speakers as mechanical wave oscillation, creating a periodic turbulence in the air that vibrates the tympanum, which vibrates the ossicles, which vibrates the fluid of the cochlea, which ultimately triggers hair cells to send electrical signals to nerves that travel to the brain. Each time the signal travels from one neuron to another it must be transduced from electrical to chemical energy while traveling through the intercellular synapse. Thus the acoustic, the technological, and the biological harmonize with one another in a biological soundscape. However, this biological soundscape is in turn culturally transduced, obscuring the technical conditions of its production.

\section{Interior Time}

Sound triangulates between space and time, drawing attention to the physical medium through which it is transmitted. It places objects in space and floods space with time.

Space indexes the distribution of sounds and time indexes the motion of sounds. Yet acoustic time is always spatialized; sounds are sensed as connecting points up and down, in and out, echo and reverb, pointsource and diffuse. And acoustic space is likewise temporalized; sounds are heard moving, locating, placing points in time. The placing of auditory time is the sonic envelope created from the layered attack, sustain, decay, and resonance of sounds. The placing of auditory space is the dispersion of sonic height, depth, and directionality. ${ }^{41}$

Sonocytology captures vibrations caused by intracellular processes unfolding in cytoplasmic milieus. Pressing our ears to opaque cell walls, we

39. Connor, "Michel Serres' Five Senses," pp. 323-24.

40. On the relation of sound to matter, Deleuze and Guattari claim "it is a question of a highly complex and elaborate material making audible nonsonorous forces" (Deleuze and Guattari, A Thousand Plateaus, p. 95).

41. Steven Feld, "Places Sensed, Senses Placed: Toward a Sensuous Epistemology of Environments," in Empire of the Senses, p. 185. 
hear cellular activity unfold in four dimensions: the busy hum of actin and myosin filaments assembling cellular scaffolding, the whoosh of molecular transport through cytosol, the glub glub of endocytosis and exocytosis. The question remains as to how sound indexes these dynamic interior biological processes and how temporality is fractured by biologists' conceptualizations of the insides of cells.

Sonocytology has been met with reserve and occasional skepticism in the scientific world. Some are unsure whether the sound recorded by the AFM originates within the cells and have raised the possibility that the vibrations could be due to external factors, such as Brownian motion or the unintentional movement of the AFM probe. However, Gimzewski and Pelling are certain that what they are hearing is the sound of cellular metabolism and the movement of motor proteins, positing that their "experiments reveal a new aspect of yeast cell biology-the dynamic nanomechanical activity of the cell wall" ("L," p. 1150; emphasis added). The fact that the frequency of cellular sounds depends upon the temperature and metabolism of the yeast strongly supports their claim.

Gimzewski compares the AFM reading the topology of a microscopic surface to a blind person running his finger over a line of braille. ${ }^{42}$ Instead of running the tip of the probe over a surface, however, Gimzewski holds the probe in place over a yeast cell and measures the displacement of the cell wall, a technique he compares to "using your finger to feel a pulse" (" $R$ "). Comparing cellular movement to a beating heart is not accidental; the beating heart stands as an icon of life and motion. ${ }^{43}$ Mediate auscultation, tissue culture, cinematography, and atomic force microscopy have listened to, isolated, visualized, or probed hearts in an attempt to get closer to the locus of organismic vitality.

One of the first tissues to be kept alive outside of an animal body was a culture of chicken heart cells. Heart cells were chosen "from all the possible organs and tissues of the body, to demonstrate 'permanent life' and rejuvenation by culture with a tissue that would manifest life most obviously: the beating heart." 44 Heart cells that continued to beat in culture constituted the most publicly convincing demonstration of artificially sustained life in part because both scientists and laypeople could associate beating hearts with the lively rhythm of their own bodies. "The combination of this

42. See Gimzewski and Victoria Vesna, "The Nanoneme Syndrome: Blurring of Fact and Fiction in the Construction of a New Science," Technoetic Arts 1, no. 1 (2003): 10.

43. See Shigehisa Kuriyama, The Expressiveness of the Body and the Divergence of Greek and Chinese Medicine (New York, 1999).

44. Hannah Landecker, Culturing Life: How Cells Became Technologies (Cambridge, Mass., 2007), p. 97. 
natural animate function that every reader could feel thumping away within themselves and the familiar, everyday inanimate object of the glass jar ... resulted in the distinctly uncanny image of life continuing severed from the body and contained in glass." 45

Scientists marveled as heart cells continued to beat autonomously outside of the animal, as if the rhythmic movement of the cells made them more alive than stationary cells. Half a century earlier, Étienne-Jules Marey, who invented techniques for representing physiological mechanics and animal locomotion, developed instruments like the cardiograph and the sphygmograph to measure the pulse. In one experiment he inserted air-filled ampules into a horse's beating heart and recorded its contractions using a kymograph. ${ }^{46}$ In one of the first uses of the cinematograph for the study of animal physiology, Ludwig Braun filmed the contractions of a dog's heart in 1898.47

The heart is also central to the application of atomic force microscopy to biological research; the mechanical pulse of embryonic chicken cardiomyocytes in culture is a primary object of analysis using the AFM in biophysics, as is the movement of cilia and flagella. ${ }^{8}$ But prior to Gimzewski's idea to convert AFM data to sound the pulsing and vibrating of cells had only been measured graphically. Gimzewski first conceived of sonocytology in 2001, when he learned from his colleague Ventura that cardiomyocytes grown in culture contract and relax rhythmically in a Petri dish. He wondered whether other cells also pulsated and, if so, whether those fluctuations could be within the range of human hearing. As in earlier experiments with measuring a heartbeat, the animation of heart stem cells in Gimzewski's lab is easily invested with life. Science journalist Margaret Wertheim, upon seeing Gimzewski's heart cells in culture, exclaimed: "Though there is no body here, no actual organ, rhythmic waves course through the cell community. It's an eerie sight, as if the culture were straining toward organismic identity. This phenomenon has inspired Right-toLifers to declare that an 18-day-old fetus has a heart and is, hence, a fully charged human: I beat, therefore I am." 49

Hannah Landecker, in her history of in vitro life, elucidates the connection between understandings of the interior and exterior of an organism

45. Ibid.

46. See Lisa Cartwright, Screening the Body: Tracing Medicine's Visual Culture (Minneapolis, 1995), pp. 24-26.

47. See ibid., p. 20.

48. See Jan Domke et al., "Mapping the Mechanical Pulse of Single Cardiomyocytes with the Atomic Force Microscope," European Biophysics Journal 28, no. 3 (1999): 179-86.

49. Wertheim, "Buckyballs and Screaming Cells," p. 29. 
and notions of time. Before tissue culture, scientists who wanted to represent different stages in a biological process over time had to kill organisms or tissues at each successive stage of the process being studied in order to create a composite image of, for example, cell growth and division. By taking tissue out of the interior milieu of the organism and placing it in an external, artificial milieu scientists were able for the first time to watch interior biological activity unfold under glass: "Internal processes could be placed on the exterior, and watched.... Something opaque was replaced by something transparent, and the enclosure did not have to be opened or halted in order to observe what was going on inside it." ${ }_{50}$

The "vibrating world," of which sound is but a small, biologically mediated, fraction likewise reveals interior processes, making the interior time accessible, immediate, and mediated outside of the cell..$^{51}$ While scientists cannot examine cellular activity outside of the cytoplasmic milieu, the cellular interior can be sonically projected into an external acoustic space. Sonocytology, like tissue culture, turns the body inside out in order to render dynamic interior processes accessible.

Listening to the soothing hum and thump of yeast metabolism allows one to imaginatively project a listening body into the milieu of yeast. Sound maps the dimensions and characteristics of the acoustic space through which it is propagated; sound waves originating in one place extend outward in concentric circles, slowing their pace through liquid media, diffracting or reflecting off of walls and solid objects. Such qualities of sound, for instance, are utilized in sonar (sound navigation and ranging) to orient objects underwater. Sonocytology orients listeners to intracellular activity, clueing listeners in to the dynamism on the other side of the cell wall.

Sound has been used in science to explore and gain direct experience of inaccessible places: to sound the depth of an ocean, the inside of a body, and the furthest reaches of space. ${ }^{2}$ Acoustic technology is also used to connect with absent loved ones, as when telephone wires and satellites transmit disembodied voices, or with people on the margins of life, as in the use of early sound recording to embalm the voices of the dying and the

50. Landecker, "New Times for Biology: Nerve Cultures and the Advent of Cellular Life in Vitro," Studies in History and Philosophy of Biological and Biomedical Sciences 33, no. 4 (2002): 690.

51. Sterne, The Audible Past, p. 11.

52. In space, the further away a sound originates the older it is. Cosmologists recently analyzed sound waves originating in the early universe to extrapolate the age and structure of the universe. See C. L. Bennett et al., "First Year Wilkinson Microwave Anisotropy Probe (WMAP) Observations: Preliminary Maps and Basic Results," The Astrophysical Journal Supplement Series 148 (Sept. 2003): 1-27. 
more recent use of ultrasound in obstetrics. ${ }^{53}$ To say that a cell is speaking is to project cultural notions of what it means to be human, to be subjective and have agency, and even for something to be meaningful, into a cellular milieu. Perhaps sonocytology is a mode of imperialism, seizing a cellular colony and asking that its epistemology resonate with our own. This possibility reminds us of the limits of scientific representations: to listen to a cell is always to speak for it.

53. See Kittler, Gramophone, Film, Typewriter, and Avital Ronell, The Telephone Book: Technology-Schizophrenia-Electric Speech (Lincoln, Nebr., 1989). 